\title{
Bisphenol A levels among workers in plastic processing industry and their relations to thyroid hormones
}

\author{
Fateheya M. Metwally ${ }^{1}$, Adel Hasheesh ${ }^{2}$, Mohamed M. Zaid ${ }^{1,4^{*}}$, Safaa Abd Fattah El Sharkawy ${ }^{3}$, Fatma Al Zahraa Mohamed \\ Abd Fattah ${ }^{3}$, Manal Soliman Mazhar ${ }^{3}$ \\ ${ }^{1}$ Department of Environmental and Occupational Medicine, National Research Centre, Egypt. \\ ${ }^{2}$ Department of Children with Special Needs, National Research Centre, Egypt. \\ ${ }^{3}$ Department of Occupational Medicine, Faculty of medicine, Al-Azhar University, Egypt. \\ ${ }^{4}$ Department of Chemistry, College of Sciences and Arts-Rabigh, King Abdulaziz University, KSA.
}

\begin{tabular}{|c|c|}
\hline ARTICLE INFO & ABSTRACT \\
\hline Received on: 28/07/2019 & Bisphenol A(BPA) is widely used in the plastic processing industry. A cross-sectional study was conducted to measure \\
\hline Accepted on: 19/09/2019 & BPA levels in the serum of workers as a biomarker of occupational exposure, investigate the thyroid hormone profile \\
\hline Available online: 04/11/2019 & $\begin{array}{l}\text { among BPA exposed workers, and identify the relationship between occupational exposure to BPA and thyroid } \\
\text { hormones during. Our data indicate that the studied workers had higher BPA level than that reported for the Egyptian }\end{array}$ \\
\hline $\begin{array}{l}\text { Key words: } \\
\text { Bisphenol A, occupational } \\
\text { exposure, thyroid hormones, } \\
\text { serum BPA. }\end{array}$ & $\begin{array}{l}\text { general population, with a median serum level of } 15.6 \mathrm{ng} / \mathrm{ml} \text { and ranged from } 1.6 \text { to } 62.9 \mathrm{ng} / \mathrm{ml} \text { while the interquartile } \\
\text { range was } 16.3 \mathrm{ng} / \mathrm{ml} \text {, the highest concentration was among the workers of recycling followed by squeegees and PVC } \\
\text { departments. As regards thyroid hormones, almost one-third of the studied workers had abnormal thyroid-stimulating } \\
\text { hormone (TSH) levels and } 12.2 \% \text { had abnormal T4 levels. According to TSH and T4 levels, } 64.4 \% \text { of the studied } \\
\text { workers had normal thyroid function and } 35.6 \% \text { were suffering from subclinical hypothyroidism. No significant } \\
\text { correlation between BPA levels and subclinical hypothyroidism was statistically reported. However, our data reported } \\
\text { a significant positive correlation between thyroid hormone T3 and serum BPA concentrations. As agonist or antagonist, } \\
\text { BPA could bind to the thyroid hormone receptors indicating that remarkable endocrine disruption. }\end{array}$ \\
\hline
\end{tabular}

\section{INTRODUCTION}

One of the most volume chemicals produced globally is Bisphenol A (BPA), with more than 8 billion pounds produced annually and more than 1 million pounds released to the environment every year. Bisphenol $\mathrm{A}$ is a synthetic compound firstly recognized to be a potential synthetic estrogen then extensively utilized in plastic production (Repossi et al., 2016).

BPA is used to produce epoxy resins, polycarbonate plastic, as well as polyvinyl chloride plastics which are used to manufacture a variety of products. Therefore, various routes

\section{${ }^{*}$ Corresponding Author}

Mohamed M. Zaid, Department of Environmental and Occupational Medicine, National Research Centre, Egypt.

E-mail:mmzaid@kau.edu.sa of human exposure to this substance have been reported; these include inhalation, oral, and transdermal. Exposure to BPA may occur due to occupational exposure or from environmental sources. Occupational exposure most likely is due to manual operating activities and low levels of automation (Wang et al., 2012). Commonly, environmental BPA exposure could occur through ingestion when food was stored or reheated in containers that lined with BPA. Many other sources of human exposure such as children's toys, thermal paper, dental materials, and medical devices were previously detected (Hoekstra and Simoneau, 2013).

A lot of recent evidence prove the effect of BPA on human health. The chemical structure of BPA promotes it to fit into the estrogen receptor and acts as an endocrine disruptor. This harmful effect was reported in some experimental animal studies (Acaroz et al., 2019). Previous experimental data revealed a direct effect of the exposure to BPA on the function of the thyroid hormones, as it may disrupt the action of thyroid hormones $(\mathrm{TH})$ by interacting 
with the $\mathrm{TH}$ receptor directly, altering the metabolism of the thyroid hormones or affecting their normal delivery to target cells (Romano et al., 2015).

As regards humans, epidemiological studies have been equivocal. In US adult men's study, it was found that no associations of BPA with thyroid-stimulating hormone (TSH), free triiodothyronine $\left(\mathrm{FT}_{3}\right)$, and free thyroxin $\left(\mathrm{FT}_{4}\right)$ (Meeker et al., 2010). BPA concentrations were associated with lower total thyroxin $\left(\mathrm{TT}_{4}\right)$ in other experimental study (Meeker and Ferguson, 2011). Also, previous studies from China reported that exposure to BPA was associated with an elevation in the concentration of TSH, $\mathrm{T}_{3}$, and $\mathrm{T}_{4}$ (Wang et al., 2012; 2013).

Because of these inconclusive effects of BPA on thyroid hormones with limited studies of occupational BPA level, this study was performed to measure BPA level in the serum of workers in a plastic processing factory as a biomarker of occupational BPA exposure and to identify the relation between occupational exposure to BPA and thyroid hormones.

\section{MATERIALS AND METHODS}

The study was performed in a factory of plastic processing industry that is located at the 10th of Ramadan City, industrial zone A2,Al-Sharqiyah governorate, Egypt. This factory produces different products, such as cleaning tools, cookware as dishes, and many forms of plastics as baskets, tables, chairs, commodes, Shannon and turbo are also produced. The factory consists of many departments, including Moulding departments; Squeegees department; Breaker or granulator (crushing); Recycling department; PVC department; Decoration and finishing departments. The manufacturing processes were semiautomatic in which the raw materials and products were manually handled by the workers.

Study type and subjects: This study is a cross-sectional study, approved by the ethical committee of the National Research Centre (No.13-177), Egypt. All workers in the production line were included in the study (118 workers). According to exclusion criteria (Duration of work less than 1 year, pathological history of hyperthyroidism, thyroidectomy, thyroiditis, or hypothyroidism, taking medications affecting thyroid function, or antithyroid drugs, history of currently taking, or had previously taken thyroid hormones), 28 workers were excluded. Ultimately, 90 workers participated in the study distributed in different departments of the factory.

The study tools used were interview questionnaire that covered personal history, occupational history, and medical history. Venous blood sample was taken from each participant to measure serum BPA and thyroid hormones (TT3, TT4, and TSH) by using Enzyme-linked immunosorbent assay (ELISA) technique. BPA was assessed by using human bisphenol A ELISA kit (GSCIENCE Kit /USA) according to the method by Kodaira et al. (2000).

\section{Statistical analysis}

Data were presented as number and percentages for qualitative variables. Because serum BPA concentrations among the studied workers were not normally distributed, data will be presented as median and interquartile range. Non-parametrical Mann-Whitney $U$ test and Kruskal-Wallis test were used to compare the differences in median serum BPA concentrations. BPA was log 10-normal-transformed to get normal distributions.
Thyroid measures were presented as means and standard deviation (SD). We used Pearson correlation for thyroid hormones and logged BPA concentrations to find possible associations. The statistically significant level was set at $p \leq 0.05$.

\section{RESULTS}

The studied population includes 90 male workers, whose ages ranged from 21 to 54 years. The majority of the workers were married $(85.6 \%)$ and from rural areas $(91.1 \%)$. As regards education, almost two-thirds of the workers $(67.8 \%)$ were secondarily educated. As regards the occupational characteristics of the studied workers, the manufacturing process was a semiautomatic process. More than half of the studied workers $(56.7 \%)$ were machine operators (controlling the machine and retrieving the products), $12.2 \%$ were maintenance workers (changing the mold and maintaining the machine), and the same percentage of workers was in the finishing work (painting and packaging), while 18.9\% were in the position of dealing with chemicals (Table 1).

Serum BPA concentrations among the studied workers were ranged from 1.9 to $62.9 \mathrm{ng} / \mathrm{ml}$ and the median BPA was $15.6 \mathrm{ng} / \mathrm{ml}$ and the interquartile range was 10.2-26.5 (Table 1). On studying the factors that may affect BPA concentration, we found no statistically significant difference in the concentrations of serum BPA as regards age, residence, marital status, education, nature of work, and the duration of work of the studied workers.

Table 2 shows thyroid hormones level among the studied workers; TSH levels were above the normal range, T3 levels were in the normal range while T4 levels were below the normal range.

According to TSH level and T4 levels, workers were classified into two categories: 1-Euthyroid group: that had normal TSH level with normal T4 levels and 2-Subclinical hypothyroidism group: TSH level higher than normal but less than $10 \mu \mathrm{IU} \backslash \mathrm{ml}$ (American Thyroid Association, 2012). Based on this classification, $64.4 \%$ of the studied workers $(n=58)$ had normal thyroid function and $35.6 \%(n=32)$ had subclinical hypothyroidism. To identify the relation between serum BPA concentration and thyroid function, comparison of serum BPA among the two categories of thyroid function (Euthyroid and subclinical hypothyroidism) was done, and found that the median and interquartile range of serum BPA were lower among those with subclinical hypothyroidism than the euthyroid workers without reaching the statistically significant level (Table 3).

For detecting possible associations between BPA concentration and thyroid hormones, the pearson correlation was used (Table 4) and found that there was a positive correlation between thyroid hormone $\mathrm{T}_{3}$ and serum BPA concentration among the studied workers. Also, there was a negative correlation between TSH and serum BPA but statistically insignificant.

\section{DISCUSSION}

As countries develop and urbanize, production demands increase globally, so the exposure to BPA has steadily increased. Therefore, assessments of occupational exposure are needed to be performed, especially with the huge consumption and production of BPA containing materials and the elevation in the number of workers exposed to it worldwide (Corrales et al., 2015).

As regards bisphenol A, many studies measure BPA level among the general population in different countries, 
Table 1. Serum BPA concentrations according to the general and occupational characteristics of the studied workers.

\begin{tabular}{|c|c|c|c|c|}
\hline \multirow[b]{2}{*}{ General characteristics } & \multicolumn{3}{|c|}{ BPA (ng/ml) Mean \pm SD $19.6 \pm 14.3$} & \multirow[b]{2}{*}{ Non-parametric tests" } \\
\hline & $\begin{array}{c}\text { Median } \\
15.6\end{array}$ & $\begin{array}{c}\text { Interquartile range } \\
16.3(10.2-26.5)\end{array}$ & $\begin{array}{l}\text { Range } \\
1.9-62.1\end{array}$ & \\
\hline \multicolumn{5}{|l|}{ Age groups } \\
\hline $21-30(n=40)$ & 18.4 & $18.3(8.7-27.0)$ & $2.3-62.1$ & \multirow[t]{3}{*}{$p$ value $=0.75$} \\
\hline $31-40(n=37)$ & 14.8 & $24.0(6.4-30.4)$ & $1.9-55.3$ & \\
\hline $41-54(n=13)$ & 14.4 & $9.2(11.6-20.8)$ & $5.2-49.2$ & \\
\hline \multicolumn{5}{|l|}{ Residence } \\
\hline $\operatorname{Urban}(n=8)$ & 14.8 & $33.6(12.5-46.1)$ & $4.1-62.1$ & \multirow[t]{2}{*}{$p$ value $=0.47$} \\
\hline Rural $(n=82)$ & 15.6 & $18.6(7.7-26.3)$ & $1.9-55.3$ & \\
\hline \multicolumn{5}{|l|}{ Marital status } \\
\hline Single $(n=13)$ & & $20.2(15.2-35.4)$ & $3.6-52.1$ & \multirow[t]{2}{*}{$p$ value $=0.12$} \\
\hline Married $(n=77)$ & 14.5 & $20.3(6.4-26.7)$ & $1.9-62.1$ & \\
\hline \multicolumn{5}{|l|}{ Education } \\
\hline Primary $(n=19)$ & 14.5 & $23.0(11.2-34.2)$ & $1.9-46.2$ & \multirow[t]{3}{*}{$p$ value $=0.95$} \\
\hline Secondary $(n=61)$ & 15.9 & $17.7(9.2-26.9)$ & $2.1-55.3$ & \\
\hline High education $(n=10)$ & 14.9 & $23.1(4.6-27.7)$ & $2.1-62.1$ & \\
\hline \multicolumn{5}{|l|}{ Nature of work } \\
\hline Machine Operators $(n=51)$ & 15.4 & $15.9(6.5-22.4)$ & $1.9-50.1$ & \multirow[t]{4}{*}{$p$ value $=0.36$} \\
\hline Maintenance workers $(n=11)$ & 14.5 & $25.9(8.2-34.1)$ & $4.8-55.3$ & \\
\hline Deal with chemicals $(n=17)$ & 19.7 & $25.9(10.3-36.2)$ & $4.2-47.2$ & \\
\hline Finishing workers $(n=11)$ & 9.2 & $44.1(5.1-49.2)$ & $5.1-49.2$ & \\
\hline \multicolumn{5}{|l|}{ Duration of work } \\
\hline $1-10$ years $(n=61)$ & 19.36 & $21.2(7.3-28.5)$ & $1.9-62.1$ & \multirow[t]{2}{*}{$p$ value $=0.62$} \\
\hline$>10$ years $(n=29)$ & 14.4 & $10.6(10.2-20.8)$ & $2.1-55.3$ & \\
\hline
\end{tabular}

"Mann-Whitney test and Kruskal-Wallis test for median. BPA = bisphenol A.

Table 2. Serum thyroid hormones measures of the studied workers.

\begin{tabular}{lccc}
\hline \multirow{2}{*}{ Thyroid Hormones } & \multirow{2}{*}{ Reference normal range $\dagger$} & \multicolumn{2}{c}{ Studied workers } \\
\cline { 3 - 4 } & & Range & Mean \pm SD \\
\hline $\mathrm{TSH}(\mu \mathrm{IU} / \mathrm{ml})$ & $0.35-4.5$ & $0.4-9.5$ & $4.1 \pm 2.2$ \\
$\mathrm{~T}_{3}(\mathrm{ng} \backslash \mathrm{dl})$ & $75-189$ & $77-189$ & $129 \pm 26$ \\
$\mathrm{~T}_{4}(\mu \mathrm{g} \backslash \mathrm{dl})$ & $4.5-12.5$ & $3.3-12.5$ & $7.7 \pm 2.5$ \\
\hline
\end{tabular}

Reference normal range according to the American Thyroid Association, (2012). $\mathrm{TSH}=$ thyroid-stimulating hormone.

Table 3. Serum BPA among the studied workers according to their thyroid function status.

\begin{tabular}{lccccc}
\hline \multirow{2}{*}{$\begin{array}{l}\text { Thyroid function } \\
\text { status }\end{array}$} & \multicolumn{2}{c}{ Total $=\mathbf{9 0}$} & \multicolumn{2}{c}{ BPA (ng/ml) } & Mann-Whitney \\
\cline { 2 - 5 } & \multicolumn{2}{c}{$\boldsymbol{N} \%$} & Median & $\begin{array}{c}\text { Interquartile } \\
\text { range }\end{array}$ & $\begin{array}{c}\text { test } \\
\text { Euthyroid }\end{array}$ \\
\hline $\begin{array}{l}\text { Subclinical } \\
\text { hypothyroidism }\end{array}$ & $N=32$ & $64.4 \%$ & 16.3 & $21.6(11.0-32.6)$ & $p$ value $=0.09$ \\
\hline
\end{tabular}

$\mathrm{BPA}=$ bisphenol $\mathrm{A}, \mathrm{TSH}=$ thyroid-stimulating hormone.

(Calafat et al., 2008; Health Canada, 2010; Park et al., 2017; Wang et al., 2013), whereas only a few studies have measured exposures to BPA in the workplace. So, studies to investigate occupational exposure to BPA and its related hazards effect are urgently needed.

In the present work, BPA was detected in the serum of all participants. Serum BPA concentrations were ranging from 1.9 to
Table 4. Correlation between serum BPA and thyroid hormones.

\begin{tabular}{lcc}
\hline Thyroid hormones & Correlation coefficient & $\boldsymbol{p}$-value \\
\hline $\mathrm{T}_{3}$ & 0.237 & 0.02 \\
$\mathrm{~T}_{4}$ & 0.061 & 0.56 \\
$\mathrm{TSH}$ & -0.122 & 0.25 \\
\hline
\end{tabular}

Serum BPA was log 10-normal-transformed to achieve normal distribution. $\mathrm{BPA}=$ bisphenol $\mathrm{A}, \mathrm{TSH}=$ thyroid-stimulating hormone.

$62.9 \mathrm{ng} / \mathrm{ml}$ and the median was $15.6 \mathrm{ng} / \mathrm{ml}$. This is in accordance with Zhuang et al. (2015) who reported that the median serum BPA level was $18.75 \mathrm{ng} / \mathrm{ml}$ and the range was from undetectable up to $98.5 \mathrm{ng} / \mathrm{ml}$ in workers exposed to BPA in epoxy resin industry in China. On the other hand, Xiao et al. (2009) reported that the median serum BPA concentration was $101.9 \mu \mathrm{g} / 1$ among 20 occupationally exposed workers in China. On the contrary, Zhou et al. (2013) found that median serum BPA concentration was 3.19 $\mu \mathrm{g} / \mathrm{l}$ in a study upon workers in a petrochemical company. These wide differences in BPA levels might be explained by the fact that some factories used BPA as pure raw materials, while others used it as additives. In addition, workers exposures are affected by different factors as whether industrial processes are manual or automatic, the existence, type and efficiency of protective measures used, also, in determining BPA levels, different analytical and measuring methods are used. In comparing the results of this work with other studies, Wang et al. (2012) reported a level ranged from 12.5 to $164.5 \mathrm{ng} / \mathrm{ml}$ of BPA in the urine of workers from two epoxy 
resin factories in china. Recently, Kouidhi et al. (2017) found that the interquartile range of urinary BPA was $2.03-4.99 \mathrm{ng} / \mathrm{ml}$ among 70 workers of plastic injection moulding factory in Malaysia. Although these studies were among occupationally exposed workers, they cannot be compared with the results of this study because, in the current study, BPA was measured in serum while they measured BPA in urine with different measuring methods. However, these occupational studies concluded that the BPA level among occupationally exposed workers was higher than that of the general population.

Nature of the work and the duration of work are the important occupational characteristics that may influence the exposure at the workplace. In this study, serum BPA concentrations were insignificantly higher among the workers who worked for 10 years or less than those who worked for more than 10 years (Table 1). These come in accordance with Mohamed et al. (2012) who found that work duration was not related to urinary BPA level among the workers of the fiberglass pipe industry in Egypt. On contrary to this finding, Zhuang et al. (2015) reported that work duration had a significant positive association with serum BPA level. These controversial findings maybe because there is no final proof of the accumulation potential of BPA in the human body (Corrales et al., 2015). However, the findings in the current study may be explained by the pharmacokinetics of BPA, as BPA is rapidly metabolized and excreted through kidneys with approximately 6 hours biological half-life, within 24 hours of complete urinary excretion (Vandenberg et al., 2012).

As regards the abnormality of thyroid hormones among the studied workers, it was found that 32 workers $(35.6 \%)$ had subclinical hypothyroidism. Human studies concerned with the prevalence of thyroid hormone abnormalities among occupational settings are much lacking. However, the prevalence of subclinical hypothyroidism reported in this research is much higher than that reported by Soliman et al. (2013), Metwalley and E-Saied (2014), and Unnikrishnan et al. (2013). So, the finding of the present study about the high prevalence of subclinical hypothyroidism (35.6\%) acts as an alarming sign that evokes many questions like, is this high prevalence specific for the workers in the studied factory or involve the workers of other plastic processing industry? and if there is a causal relationship to chemicals involved in the plastic processing industry or related to environmental pollutants? also what about the general population? Further research on a large scale not only on plastic workers but also on the general population is urgently needed to answer these questions.

To identify the relation between serum BPA concentration and thyroid function, comparison of serum BPA among the two categories of thyroid function (Euthyroid and subclinical hypothyroidism) was done, and found that the median and interquartile range of serum BPA were lower among those with subclinical hypothyroidism than the euthyroid workers without reaching the statistically significant level (Table 4). This means that serum BPA has no effect on TSH levels among the exposed workers. This finding is in agreement with Sugiura-Ogasawara et al. (2005) who reported unchangeable BPA mean values between patients with and without hypothyroidism. Also, Wang et al. (2013) found a lower urinary BPA on subjects with overt or subclinical hypothyroidism in comparison with the euthyroid group. As in our study, no relation was detected between the levels of serum BPA and subclinical hypothyroidism among the studied workers of plastic processing industry, this hypothyroidism condition may be attributed to many other factors as plastic workers deal with different chemical compounds, some of them had endocrine disruptor effects as brominated flame retardants, phthalates, as well as BPA. Also, plastic workers are exposed to complex mixtures of chemicals whose combined effects on health may be more than their individual ones. In addition, plastic workers are also exposed to environmental pollutants which may affect thyroid function as dioxin, perchlorate, and some pesticides and heavy metals.

For further exploration of the relation between BPA and thyroid hormones, the correlation was done and found that there was a statistical significant positive correlation with $\mathrm{T} 3$ and an insignificant negative correlation with TSH among the studied workers. That is the same finding of Wang et al. (2012) who found that increasing urinary BPA levels in exposed workers was accompanied by rose of T3 and dropped in TSH levels, although this drop was not significant. Also, Wang et al. (2013) reported a positive association of urinary $\mathrm{BPA}$ and $\mathrm{FT}_{3}$ and inverse association with $\mathrm{TSH}$ among 3,394 non-occupationally exposed Chinese population. On the contrary, Meeker et al. (2010) found a weak inverse association between BPA and TSH but they observed no association of BPA with total T3 in male patients from infertility clinics. Also, Meeker and Ferguson (2011) using data from US NHANES 2007-2008 reported no relation between BPA and TSH in 1,346 adults and they observed an inverse correlation between BPA and total T4.

These controversial results may be explained by the complex mechanism of action of BPA as endocrine disruptors. Because of the structural similarity of BPA to thyroid hormone, BPA binds to thyroid hormone receptors and acts as an agonist or antagonist of thyroid hormone receptor. Also, there is evidence from experimental studies indicating that BPA inhibits the secretion of TSH at the pituitary level and suppresses TSH release a way that is independent of the thyroid hormone feedback mechanism (Sriphrapradang et al., 2013). Such mechanism might be more difficult to understand, as the receptors of thyroid hormones might not be a direct target of BPA but instead another factor might be involved, as BPA was observed to have a direct effect on thyroid follicular cells and leads to inhibit transcriptional activity that promoted by $\mathrm{T} 3$ in a dose-dependent mechanism in the transient gene expression experiments (Chailurkit et al., 2006). $\mathrm{xSo}$, it seems agreeable that BPA would not produce patterns of disorders that simulate thyroid hormone insufficiency or excess.

Although the studies did not provide a conclusive finding of the exact effect of BPA on thyroid hormones, they supported the evidence that BPA is thyroid disruptor.

\section{CONCLUSION}

The studied workers in that factory of the plastic processing industry had bisphenol A levels higher than that reported for the Egyptian general population. As regards thyroid function, it was found that almost one-third of the studied workers had subclinical hypothyroidism. However, this finding was not significantly related to BPA levels. There was a statistically significant positive correlation between thyroid hormone triiodothyronine $\left(\mathrm{T}_{3}\right)$ and serum BPA concentrations.

Consequently, we recommended that there is a great need for environmental and biological monitoring of BPA exposure not only in the present factory but also in all plastic processing industries, and occupations in which workers are suspected to 
exposed to a high BPA level. Raise the awareness of the general population and environmental concerning agencies about BPA exposure, its health effects, and how to limit its danger. Further studies among the general population and occupationally exposed workers are needed for more identification of the effects of BPA exposure on thyroid and other body systems.

\section{CONFLICT OF INTEREST}

The authors declare that there are no conflicts of interest in this article.

\section{FUNDING}

None.

\section{REFERENCES}

Acaroz U, Ince S, Arslan-Acaroz D, Gurler Z, Demirel HH, Kucukkurt I, Eryavuz A, Kara R, Varol N, Zhu K. Bisphenol-A induced oxidative stress, inflammatory gene expression, and metabolic and histopathological changes in male Wistar albino rats: protective role of boron. Toxicol Res (Camb), 2019; 8(2):262-9.

American Thyroid Association. Thyroid function tests, 2012 Available via https://www.thyroid.org/thyroid-function-tests/

Calafat A, Ye X, Wong L, Reidy J, Needham L. Exposure of the U.S. population to bisphenol A and 4-tertiary-octylphenol: 2003-2004. Environ Health Perspect, 2008; 116:39-44.

Chailurkit L, Aekplakorn W, Ongphiphadhanakul B. The association of serum bisphenol A with thyroid autoimmunity. Int J Environ Res Public Health, 2006; 13:1153.

Corrales J, Kristofco L, Steele W, Yates B, Breed C, Williams E, Brooks BW. Global assessment of bisphenol A in the environment review and analysis of its occurrence and bioaccumulation. Dose Response, 2015; 13(3).

Health Canada. Report on human biomonitoring of environmental chemicals in Canada. Results of the Canadian Health Measures Survey Cycle 1 (2007-2009). Canada.ca, Ottawa, Ontario, 2010.

Hoekstra E, Simoneau C. Release of bisphenol A from polycarbonate: a review. Crit Rev Food Sci Nutr, 2013; 53:386-402.

Kodaira T, Kato I, Li J, Mochizuki T, Hoshino M, Usaki Y, Oguri

$\mathrm{H}$, Yanaihara N. Novel ELISA for the measurement of immunoreactive bisphenol A. Biomed Res, 2000; 21:117-21.

Kouidhi W, Thannimalay L, Soon C, Ali M. Occupational exposure to bisphenol A (BPA) in a plastic injection molding factory in Malaysia. Int J Occup Med Environ Health, 2017; 30(5):743-50.

Meeker J, Ferguson K. Relationship between urinary phthalate and bisphenol A concentrations and serum thyroid measures in U.S. Adults and adolescents from the National Health and Nutrition Examination Survey (NHANES) 2007-2008. Environ Health Perspect, 2011; 119:1396-402.

Meeker J, Calafat A, Hauser R. Urinary bisphenol A concentrations in relation to serum thyroid and reproductive hormone levels in men from an infertility clinic. Environ Sci Technol, 2010; 44:1458-63.

Metwalley K, E-Saied A. Thyroid abnormalities in Egyptian children and adolescents with type 1 diabetes mellitus: a single center study from Upper Egypt. Indian J Endocrinol Metab, 2014; 18(5):637-41.

Mohamed A, Hussein A, Mohamed S, Rashed L. Endocrinal disruption among workers exposed to bisphenol A in fiberglass pipes industry, submitted in partial fulfillment of the requirements for M.SC. Degree in industrial medicine and occupational diseases, Cairo University, Giza, Egypt, 2012.
Park J, Seyoung K, Minkyu P, Yeji K, Hyeeun L, Hyunrim C, Sinye L. Relationship between dietary factors and bisphenol a exposure: the second Korean National Environmental Health Survey (KoNEHS 2012 2014). Ann Occup Environ Med, 2017; 29:42-56.

Repossi A, Farabegoli F, Gazzotti T, Zironi E, Pagliuca G. Bisphenol A in edible part of seafood. Ital J Food Saf, 2016; 5(2):5666.

Romano ME, Webster GM, Vuong AM, Thomas Zoeller R, Chen A, Hoofnagle AN, Calafat AM, Karagas MR, Yolton K, Lanphear BP, Braun JM. Gestational urinary bisphenol A and maternal and newborn thyroid hormone concentrations: the HOME Study. Environ Res, 2015; 138:453-60.

Soliman G, Bahagt N, EL-mofty Z. Prevalence of thyroid disorder in Egyptian children with type I diabetes mellitus and the prevalence of thyroid antibodies among them. Thyroid Disorders, 2013; 1:118.

Sriphrapradang C, Chailurkit L, Aekplakorn W, Ongphiphadhanakul B. Association between bisphenol A and abnormal free thyroxin level in men. Endocrine, 2013; 44(2):441-7.

Sugiura-Ogasawara M, Ozaki Y, Sonta S, Makino T, Suzumori $\mathrm{K}$. Exposure to bisphenol A is associated with recurrent miscarriage. Hum Reprod, 2005; 20:2325-29.

Unnikrishnan A, Kalra S, Sahay S, Bantwal G, John M, Tewari N. Prevalence of hypothyroidism in adults: An epidemiological study in eight cities of India. Indian J Endocrinol Metab, 2013; 17(4):647-52.

Vandenberg L, Colborn T, Hayes T, Heindel J, Jacobs D, Lee D, Shioda T, Soto A, vom Saal F, Welshons W, Zoeller R, Myers J. Hormones and endocrine-disrupting chemicals: low-dose effects and nonmonotonic dose responses. Endocr Rev, 2012; 33:378-455.

Wang F, Hua J, Chen M, Xia Y, Zhang Q, Zhao R, Zhou W, Zhang Z, Wang B. High urinary bisphenolA concentrations in workers and possible laboratory abnormalities. OccupEnviron Med, 2012; 69:679-84.

Wang T, Lu J, Xu M, Xu Y, Li M, Liu Y, Tian X, Chen Y, Dai M, Wang W, Lai S, Bi Y, Ning G. Urinary Bisphenol A concentration and thyroid function in Chinese adults. Epidemiology, 2013; 24:295-302.

Xiao GB, Wang RY, Cai YZ, He GH, Zhou ZJ. Effect of bisphenol A on semen quality of exposed workers: a pilot study. Chinese J Ind Hyg Occ Dis, 2009; 27:741-43.

Zhou Q, Miao M, Ran M, Ding L, Bai L, Wu T, Yuan W, Gao E, Wang J, Li G, Li DK. Serum bisphenol A concentration and sex hormone levels in men. Fertil Steril, 2013; 100(2):478-82.

Zhuang W, Wu K, Wang Y, Zhu H, Deng Z, Peng L, Zhu G.Association of serum bisphenol-A concentration and male reproductive function among exposed workers. Arch Environ Contam Toxicol 2015; 68(1):38-45.

How to cite this article:

Metwally FM, Hasheesh A, Zaid MM, El Sharkawy SAF, Fattah FAZMA, Mazhar MS. Bisphenol A levels among workers in plastic processing industry and their relations to thyroid hormones. J Appl Pharm Sci, 2019; 9(11): 107-111. 